UDC 635.71:546.48

$635.71: 546.62$

504.5:669.018.674

COBISS.SR-ID 250170124

Original research paper

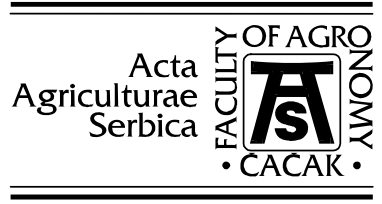

Acta Agriculturae Serbica, Vol. XXII, 43 (2017); 57-65

\title{
Biochemical responses of basil to aluminium and cadmium stresses
}

\author{
Selma Đogić ${ }^{1}$, Naida Džubur ${ }^{1}$, Erna Karalija ${ }^{1}$, Adisa Parić ${ }^{1}$ \\ ${ }^{1}$ Laboratory for Plant Physiology, Biology Department, Faculty of Natural \\ Sciences and Mathematics, University of Sarajevo \\ Corresponding author: adisa.p@pmf.unsa.ba
}

\begin{abstract}
The effect of aluminium and cadmium on growth and physiological parameters in 60 days old basil seedlings (Ocimum basilicum L.) grown in polluted soil were investigated. Control plants, grown in unpolluted soil, were used for evaluation of the heavy metal effect. Growth parameters were analysed immediately after sample collection, leaf area and plant height were recorded. Analysis of secondary metabolite, proline, total carbohydrates content and antioxidant capacity in 60 days old seedlings was performed. The antioxidant activity of basil extracts was determined by the DPPH method, and results showed an increase of antioxidative capacity in basil seedlings exposed to heavy metal stress due to the activation of antioxidative system in plant cells. Maximum production of secondary metabolites was recorded for seedlings exposed to $100 \mathrm{mg} / \mathrm{kg}$ soil Cd and Al. Results showed that cadmium stress increased concentration of proline, while aluminium did not had that effect. The content of total carbohydrates remained almost unchanged, with exception of basil seedlings grown on soil containing $50 \mathrm{mg} / \mathrm{kg} \mathrm{AlCl}_{3}$.
\end{abstract}

Keywords: aluminium, cadmium, basil, DPPH, secondary metabolites 


\section{Introduction}

Tolerance of plants depends on their ability to survive and reproduce under different environmental stresses (Redondo-Gomez, 2013). Nowadays one of the most serious problems for the environment is an increase of heavy metals pollutions (Golubović and Blagojević, 2012). The increased concentrations of heavy metals have a negative effect on biomass and soil fertility, but ultimately they could significantly harm human health (Gratão et al., 2005).

Cadmium is a non-essential element which has a high toxicity even at low concentrations ( $\mathrm{Xu}$ et al., 2006), and in plants inhibits their growth and development, synthesis of chlorophyll, carotenoids and ATP, also causes leaf chlorosis, has influence on the function of enzymes in various metabolic pathways and decreases photosynthetic activity (Sharma and Dubey, 2006).

It is established that aluminium interferes with cell division in root tips and lateral roots, decreases root respiration, reduces accumulation of polysaccharides in the cell wall, lessens the production and transport of cytokinins as well as the water uptake, and interferes with the uptake, metabolism and transport of several crucial nutrients (Mossor-Pietraszewska, 2001).

Pollutants such as heavy metals are mainly introduced into the food chain through the root system of plants (Yadav, 2010). Homeostasis in plants is maintained by balance between the production of ROS and detoxification performed by the antioxidative system. Therefore, if the balance is disturbed by heavy metals stress, plants suffer the oxidative stress. Tolerance of stress corresponds to an increase in capacity for the removal of reactive oxygen species. Oxidative stress can lead to inhibition of photosynthesis and respiration (Sharma and Chakraverty, 2013) and production of huge number of secondary metabolites (Wink, 2010).

The higher amount of proline reduces membrane damage, regulates redox potential, decreases cell acidity, protects molecules from denaturation and provides a role of non-enzymatic antioxidants (Bacelar et al., 2012). The survival of plants is closely associated with carbohydrates, respiration substrates. Morphological and physiological responses of terrestrial plants provide positive effects of carbohydrates, as well as maintaining higher concentration of carbohydrates in roots, which facilitates survival (Pradhan and Mohanty, 2013).

The aim of this work was to evaluate biochemical responses of basil (Ocimum basilicum L.) to $\mathrm{Al}$ and $\mathrm{Cd}$ treatments. It was studied effects of heavy metals on the content of secondary metabolites, proline, carbohydrate and antioxidant activity of basil.

\section{Materials and methods}

To perform the experiment, seeds of basil (Ocimum basilicum L.) were used, which were planted in the soil (previously dried for five days at room 
temperature). A randomized block design experiment was arranged in the Laboratory for Plant Physiology, Department of Biology University of Sarajevo. Seeds were sown in pots $(25 \times 25 \mathrm{~cm})$ filled with $5 \mathrm{~kg}$ of soil. In each pot 200 seeds of basil were planted. Soil in pots was mixed with different concentrations of aluminium chloride $\left(\mathrm{Al}_{2} \mathrm{Cl}_{3}\right)$ or cadmium chloride $\left(\mathrm{CdCl}_{2}\right)$. The heavy metals concentrations were $0,50,100,200 \mathrm{mg} / \mathrm{kg}$ dry soil. The pots were kept in growth chamber with 16 hours light period, temperature of $24 \pm 1^{\circ} \mathrm{C}$ and relative humidity of $60-80 \%$, by watering every other day during two months. Epigeal parts were oven-dried $\left(60^{\circ} \mathrm{C}\right)$ for $3 \mathrm{~h}$ and used for analysis.

Dry plant material was extracted with $80 \%$ methanol, left overnight on temperature of $4{ }^{\circ} \mathrm{C}$. After centrifugation, extracts were evaporated and resuspended in $80 \%$ methanol. The radical scavenging activity of the extracts was determined using 2,2-diphenyl-1-picryl-hydrazyl radical (DPPH•) method (Meda et al., 2005) and $\mathrm{IC}_{50}$ value (the concentration of extract required to inhibit $50 \%$ of DPPH free radicals) was determined. Naringenin and quercetin were applied as standard in concentration of $1 \mathrm{mg} / \mathrm{ml}$. Percentage of inhibition was compared to standard. Total phenol content was determined according to Wolfe et al. (2003), using the Folin-Ciocalteu reagent, and with gallic acid as standard. Analysis of total flavonoid content was performed according to Ordóñez et al. (2006), with catechin as standard. Analysis of total flavanols content was performed according to Gadzovska et al. (2007), with catechin as standard. All results were expressed as $\mathrm{mg}$ of used standard equivalent per $\mathrm{mg}$ of extract.

Extraction of proline was performed according to the modified method of Carillo and Gibbon (2001). Cold extraction process was used by mixing dry plant material with combination of ethanol : water $(40: 60 \mathrm{v} / \mathrm{v})$. The supernatant was collected after the mixture was left overnight at $4^{\circ} \mathrm{C}$. Quantification of proline was done by reading absorbance at $520 \mathrm{~nm}$ and using L-Proline as the standard.

Total carbohydrates content was determined according to Bartkiene (2012). Total carbohydrates were measured at $620 \mathrm{~nm}$, using glucose as a standard.

The obtained data were analyzed statistically with ANOVA in program Statistica 8.0. Each treatment was replicated three times. Standard descriptive statistical parameters were calculated for control and all treatments. Differences between treatments were determined by Post hoc test analysis of variance using Newman-Keuls test at a significance level of $1 \%(\mathrm{P} \leq 0.01)$. Calculation of the correlation coefficient by Pearson (Pearson product-moment correlation coefficient) was performed. Correlation was analyzed at the level of $5 \%$ $(\mathrm{P} \leq 0.05)$. 
a

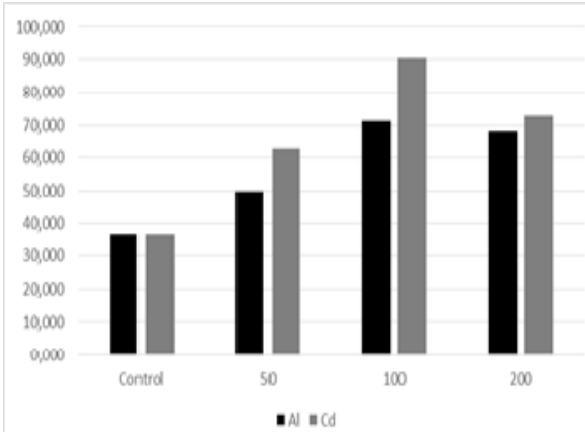

b

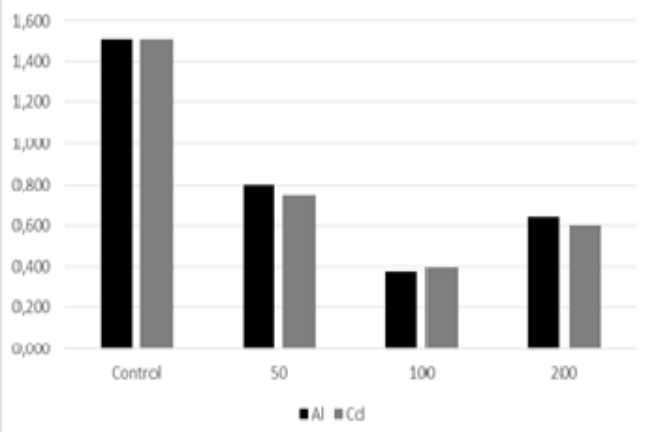

Figure 1. Percentage of antioxidative capacity (a) and $\mathrm{IC}_{50}$ values (b) in basil extracts after application of aluminium and cadmium

a

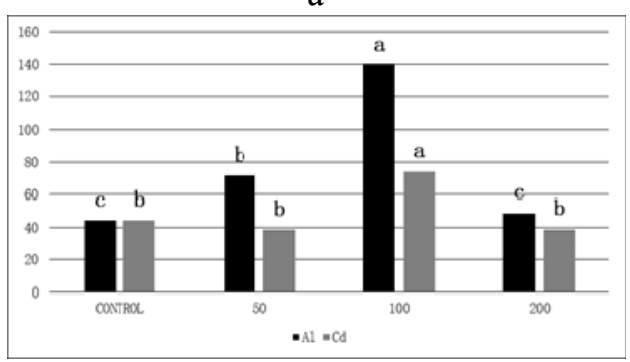

b

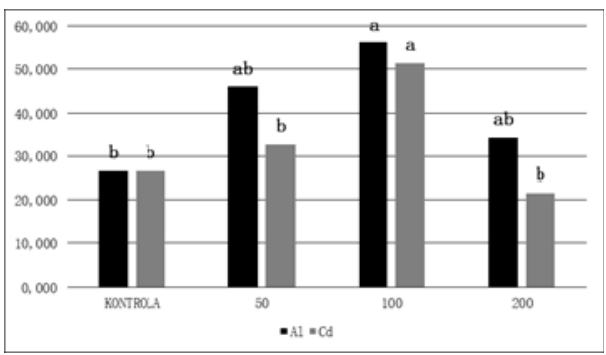

c

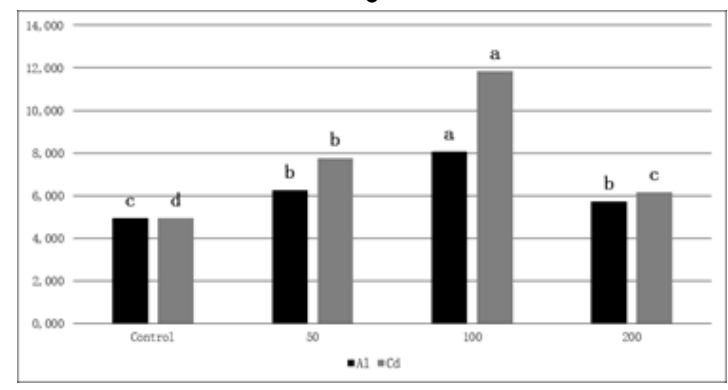

Figure 2. Variation of total phenols (a), flavonoids (b), flavanols (c) content in basil extracts after application of aluminium and cadmium Treatments not sharing the same letter above the column differ significantly after Newman-Keuls post-hoc ANOVA test at $p<0.01$ 


\section{Results}

The antioxidant capacity of methanol extracts of $O$. basilicum L., subjected to 50, 100 and $200 \mathrm{mg}$ of $\mathrm{Al}$ and $\mathrm{Cd}$ was evaluated using DPPH assays. The results of antioxidant activity showed that application of aluminium and cadmium had positive effect on inhibition of DPPH radical (Fig. 1a). Almost all of analyzed treatments are found to be stronger antioxidants than the control. The presence of $100 \mathrm{mg} \mathrm{Al}$ and $\mathrm{Cd}$ had the highest inhibition of DPPH radicals (90.171\%). The $\mathrm{IC}_{50}$ value was analysed for all tested treatments, and the highest $\mathrm{IC}_{50}$ value was registered in the control plants, indicating the lowest antioxidative activities (Fig. 1b).

The content of total phenolics, flavonoids and flavanols presented a similar pattern (Fig.2). Application of both heavy metals in concentration of $100 \mathrm{mg} / \mathrm{kg}$ soil presented the highest significant phenolic, flavonoids and flavanols content. Analysis of extracts revealed more than 50\% higher content of total phenolic, total flavonoid and total flavanols contents than samples of control plants after Al treatment and about $50 \%$ after $\mathrm{Cd}$ treatment. And other concentration of both heavy metals increased more or less secondary metabolites content. $\mathrm{Cd}$ and $\mathrm{Al}$ stress enhanced proline content, except for the treatment of $50 \mathrm{mg} \mathrm{CdCl}_{2}$ (Fig. 3).

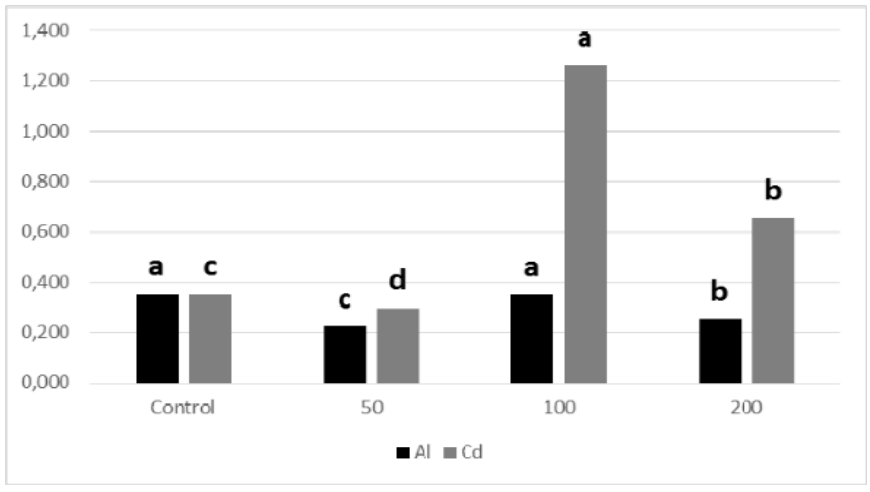

Figure 3. Variation of total proline content in basil extracts after application of aluminium and cadmium Treatments not sharing the same letter above the column differ significantly after Newman-Keuls post-hoc ANOVA test at $p<0.01$

From the results of Post-hoc Newman-Keuls test, it can be seen that increasing the concentration of cadmium or aluminium in the soil does not cause a statistically significant change $(\mathrm{p} \leq 0.01)$ in content of total carbohydrates in basil extracts. Exception was the treatment with $50 \mathrm{mg}$ of $\mathrm{AlCl}_{3}$ per $\mathrm{kg}$ of dry soil and content of sugar was $31.191 \mathrm{mg} / \mathrm{gDW}$ (Fig. 4). 


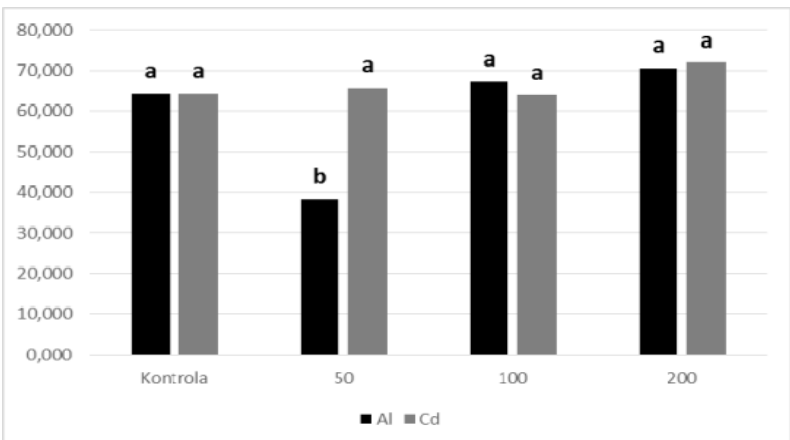

Figure 4. Variation of total carbohydrate content in basil extracts after application of aluminium and cadmium

Treatments not sharing the same letter above the column differ significantly after Newman-Keuls post-hoc ANOVA test at $p<0.01$

\section{Discussion}

Heavy metals represent a continuous risk to all living organisms including plants. Particularly, plants have their own defence mechanism to continue survival under unfavourable conditions. In this study, Ocimum basilicum plants growing under the different concentrations of heavy metal ( $\mathrm{Al}$ and $\mathrm{Cd}$ ) was examined for their capacity to antioxidative responses to heavy metal stress. Antioxidants can prevent the accumulation of ROS. Therefore, the presence of excess heavy metals could cause oxidative stress in plants, and then increase antioxidative response during high production of ROS (Dwivedi et al., 2013). Kapoor et al. (2014) reported positive correlation between concentration of $\mathrm{Cd}$ and antioxydative capacity in Brassica juncea. In this study both metals had positive correlation between antioxidant capacity and $\mathrm{IC}_{50}$ respectively.

Many studies reported production of phenolics in plants during stress conditions. Flavonoids, together with some other phenolics, contribute to the antioxidant activities of plants primarily thanks to their redox propertie (Manan et al., 2015). In this study $\mathrm{Al}$ and $\mathrm{Cd}$ application increased content of all examined secondary metabolites suggesting that flavonoids and other phenolics have an important role in the survival of plants under stress conditions. Therefore, after phenols content increasing, plants have ability of responding to toxicity caused by heavy metals, by removing reactive oxygen compounds and improving the metabolism of plants.

In stress conditions, plants accumulate compatible osmolytes such as proline, glycine, betanine, sugar alcohols. These compatible substances do not interfere with normal biochemical reactions and they act as osmoprotectans in plants under the stress. They provide protection to plants by preserving the integrity of proteins and membranes by rapid rehydration. During membrane and metabolism 
dysfunctions, they occur in the transition between the state of decreased hydration to complete dehydration. Proline is one of the most distributed osmolyte and it helps detoxify free radicals (Niknam and Ebrahimzadeh, 2002). In our investigation, an increase of proline concentration in plants treated with these two metals was established, except for $50 \mathrm{mg}$ of $\mathrm{CdCl}_{2}$. Khavari-Nejad et al., (2013) confirmed that the increase in content of proline in the extracts of different varieties of basil treated by cadmium is significant, not only because proline protects subcellular structures and macromolecules, but because it is able to protect the integrity of the protein and to increase the activity of different enzymes. Many researches established that proline stabilizes or protects natural structure of the protein regulating its hydration. In fact, the presence of water is essential to the stability of the protein structure. Therefore, proline can help maintaining the integrity and protein conformation. In general, with increasing intensity of the stress, accumulation of proline and free radicals appear in the cells. This correlation determines that the accumulation of proline is related to non-enzymatic antioxidant system. It is assumed that proline protects chloroplasts from damages (Sharmila and Saradha, 2002).

The accumulation of carbohydrates in different parts of the plant has been improved in response to different environmental stresses. The content of carbohydrates in the plant is reduced by exposure and concentration of heavy metals. Metabolism of these compounds can be affected by temperature, salinity and the presence of various ions. Increased accumulation of sugar reduces osmotic potential of the cells and another possible role of sugar is to be easily available energy source (Mohan and Hosetti, 2006; Al-Jebory, 2012).

\section{References}

A 1-Jebory E.I. (2012): Effect of water stress on carbohydrate metabolism during Pisum sativum seedlings growth. Euphrates Journal of Agriculture Science, 4 (4): 1-12.

Bacelar E.L.V.A., Moutinho-Pereira J.M., Goncalves B.M.C., Brito C.V.Q., Gomes-Laranjo J., Ferreira H.M.F., Correia C.M. (2012): Water Use Strategies of Plants Under Drought Conditions. In Aroca R. (eds), Plant Responses to Drought Stress: From Morphological to Molecular Features, SpringerVerlag, Berlin:145-171.

B artkiene E. (2012): Plant Food analysis methods. Lithuanian University of Health Sciences, Kaunas.

Carillo P., Gibon Y. (2011): Protocol: Extraction and determination of proline. In: Prometheus Wiki. Available on:

http://www.publish.csiro.au/prometheuswiki/tikipagehistory.php?page=Extraction $\% 20 \mathrm{an}$ $\mathrm{d} \% 20$ determination $\% 20 \mathrm{of} \% 20$ proline\&preview $=14$ ).

Dwivedi G.K., Upadhyay K., Mishra A.K., Singh A.K. (2013): Effect of Heavy Metals on Phenolic Content and Free Radical Scavenging Activity of Ocimum tenuiflorum L. International journal of scientific research, 2 (3): 14-16. 
Gadzovska S., Maury S., Delaunay A., Spasenoski M., Joseph C., Hagège D. (2007): Jasmonic acid elicitation of Hypericum perforatum L. Cell suspensions and effects on the production of phenylpropanoidsaandnaphtodianthrones. Plant Cell, Tissue and Organ Culture, 89: 1-13.

Golubović T., Blagojević B. (2012): Transfer and bioaccumulation of heavy metal ions from soil into plants. Safety Engineering, 2 (1): 1-4.

Gratão P.L., Polle A., Lea P.J., Azevedo, R.A. (2005): Making the life of heavy metal-stressed plants a little easier. Functional Plant Biology, 32 (6): 481494.

Kapoor D., Kaur S., Bhardwaj R. (2014): Research Article. Physiological and Biochemical Changes in Brassica juncea Plants under Cd-Induced Stress. BioMed research international. Article ID 726070, 13 pages, doi:10.1155/2014/726070726070.

Khavari-Nejad R.A., Najafi F., Angaji S.A., Shafiei, S. (2013): Molecular and Physiological Studies on Basil (Ocimum basilicum L.) Under Cadmium Stress. American-Eurasian Journal of Agricultural \& Environmental Sciences, 13 (6): 754-762.

Manan F.A., Mamat D.D., Samad A.A., Ong Y.S., Ooh K.F., Chai T.T. (2015): Heavy metal accumulation and antioxidant properties of Nephrolepis Biserrata growing in heavy metal-contaminated soil. Global NEST Journal, 17 (X): XX-XX.

Meda A., Lamien C.E., Romito M., Millogo J., Nacoulma O.G. (2005): Determination of the total phenolic, flavonoid and proline contents in Burkina Fasan Honey, as well as their radical scavenging activity. Food Chemistry, 91 (3): 571577.

Mohan B.S., Hosetti B.B. (2006): Phytotoxicity of cadmium on the physiological dynamics of Salvinia natans L. grown in macrophyte ponds. Journal of Environmental Biology, 27(4): 701-704.

Mossor-Pietraszewska T. (2001): Effect of aluminium on planth growth and metabolism. Acta Biochimica Polonica, 48 (3): 673-686.

Niknam V., Ebrahimzadeh H. (2002): Free proline content in Astragalus species. Pakistan Journal of Botany, 34 (2): 129-134.

Ordoñez A., Gomez J., Vattuone M., Isla M. (2006): Antioxidant activities of Sechiumedule (Jacq.) Swart extracts. Food Chemistry, 97: 452-458.

Pradhan C., Mohanty M. (2013): Submergence Stress: Responses and adaptations in crop plants. In Rout G.R., Das A.B. (eds), Molecular Stress Physiology of Plants, Springer, India: 331-359.

Redondo-Gomez S. (2013): Abiotic and Biotic Stress Tolerance in Plants. In Rout G.R., Das A.B. (eds), Molecular Stress Physiology of Plants, Springer, India: 1-21.

Sharma P., Dubey R.S. (2006): Cadmium uptake and its toxicity in higher plants. Narosa Publishing House, New Delhi.

Sharma J., Chakraverty N. (2013): Mechanism of Plant Tolerance in Response to Heavy Metals. . In Rout G.R., Das A.B. (eds), Molecular Stress Physiology of Plants, Springer, India: 289-309.

Sharmila P., Saradhi P.P. (2002): Proline accumulation in heavy metal stressed plants: an adaptive strategy. In Prasad M.N.V., Strzalka K. (eds), Physiology and Biochemistry of Metal Toxicity and Tolerance in Plants, Springer, Dordrecht: 179-201. 
Win M. (2010): Introduction Annual Plant, Reviews Volume 39: Functions and Biotechnology of Plant Secondary Metabolites, Second edition: 1-20.

Wolfe K., Wu X., Liu R. (2003): Antioxidant activity of apple peels. Journal of Agricultural and Food Chemistry, 51: 609-614.

Xu Z., Shen G., Zhu C., Xu L., He Y., Yu, G. (2006): Molecular mechanisms of plant resistance to cadmium toxicity. Ying yong sheng taixuebao/The journal of applied ecology/Zhongguo sheng tai xuexuehui, Zhongguokexueyuan Shenyang yingyong sheng tai yanjiusuozhu ban, 17 (6): 1112-1116.

Yadav S.K. (2010): Heavy metals toxicity in plants: an overview on the role of glutathione and phytochelatins in heavy metal stress tolerance of plants. South African Journal of Botany, 76 (2): 167-179. 